\title{
The effect of magnesium supplementation on cisplatin induced nephrotoxicity: A systematic review and meta-analysis
}

\author{
Kwanjit Danwilai ${ }^{1}$, \\ Ornrat Lohitnavy1,2, \\ Itsarawan Sakunrag1, \\ Piyameth Dilokthornsakul ${ }^{1,3^{*}}$ \\ ${ }^{1}$ Department of Pharmacy Practice, Faculty \\ of Pharmaceutical Sciences, Naresuan \\ University, Phitsanulok, Thailand \\ 2 Center of Excellence for Environmental \\ Health \& Toxicology, Faculty of \\ Pharmaceutical Sciences, Naresuan \\ University, Phitsanulok, Thailand \\ 3 Center of Pharmaceutical Outcomes \\ Research, Faculty of Pharmaceutical \\ Sciences, Naresuan University, Phitsanulok, \\ Thailand
}

*Corresponding author: Piyameth Dilokthornsakul piyamethd@nu.ac.th

Keywords:

magnesium, supplementation, cisplatin, nephrotoxicity

https://www.pharmacy.mahidol.ac.th/journal/ (C) Faculty of Pharmacy, Mahidol University (Thailand) 2021

\begin{abstract}
Nephrotoxicity is a serious side effect of cisplatin. Magnesium supplement can reduce this side effect, although previous studies demonstrated the effect on cisplatin - induced nephrotoxicity (CIN), with some showing no effect. This study aimed to summarize the effect of magnesium supplement on CIN. We systematically searched PubMed, Cochrane Library, Web of Science, Scopus, EMBASE and www.clinicaltrial.gov for all relevant studies. All clinical studies comparing the risk of CIN in patients who received magnesium supplement and the control groups were included. Our primary outcome examined the occurrence of severe nephrotoxicity. The secondary outcome was the occurrence of all grades of nephrotoxicity and changes in serum creatinine $(\mathrm{SCr})$ and creatinine clearance $(\mathrm{CrCl})$. Random-effects model was used to determine pooled effect size for nephrotoxicityrelated outcomes. A total of 4,053 studies were retrieved but only 12 studies were included. Nine studies were retrospective observational studies, while two studies were randomized controlled trials and one study was prospective study. All studies were conducted with patients that had solid tumors and receiving cisplatin $>50 \mathrm{mg} / \mathrm{m}^{2} /$ cycle.Meta-analysis indicated that magnesium supplementation could reduce the occurrence of severe CIN in the first cycle and all other cycles of cisplatin-based chemotherapy (RR $0.19,95 \% \mathrm{CI} ; 0.11-0.33$ and RR $0.28,95 \% \mathrm{CI} ; 0.19-0.43$, respectively). Similarly, changes in $\mathrm{SCr}$ and $\mathrm{CrCl}$ in the magnesium-supplemented group were significantly lower than those in the control group for both the first cycle and all other cycles $(\mathrm{p}<0.001)$. With the current evidence, magnesium supplementation possesses a protective effect for CIN, especially for severe nephrotoxicity. Oncologists may well consider supplementing magnesium for patients who are treated with cisplatin.
\end{abstract}

\section{INTRODUCTION}

Cisplatin has a well-established role in the treatment of many cancers, however, cisplatin-induced nephrotoxicity (CIN) is a common adverse effect and frequently limits its use in practice. Since cisplatin is predominantly excreted in the kidneys, the accumulation of the cisplatin in the renal tubular cells directly causes a damage to renal tubules. This results in decreased glomerular filtration rate and tubular reabsorption of electrolytes and leads to acute kidney injury and electrolyte wasting, specifically magnesium. Hence, magnesium supplementation is common practice 
for prevention of hypomagnesemia which generally occur in about 10 days after cisplatin treatment ${ }^{1-4}$. Important risk factors of CIN are dose and frequency of cisplatin administration, history of cisplatin use, patients'age, performance status measured by Eastern Cooperative Oncology Group (ECOG) scale, use of nonselective nonsteroidal anti-inflammatory drugs, hypoalbuminemia and hydration without magnesium supplementation ${ }^{5-8}$. Intravenous hydration is the standard prevention of CIN but only hydration might not be sufficient to prevent CIN.

Magnesium supplementation is an option to prevent CIN. It has been known that cisplatin causes hypomagnesemia in approximately $90 \%$ of the patients and magnesium deficiency itself may potentiate $\mathrm{CIN}^{9}$. The occurrence of $\mathrm{CIN}$ depends on the number of cycles, which reflects the cumulative dose of cisplatin ${ }^{10-13}$. Some clinical studies have reported the advantage of magnesium supplementation in CIN prevention ${ }^{8,14-24}$ but some clinical studies showed no protective effects ${ }^{25-27}$. To date, there is also no international guidelines which highly recommend magnesium supplement in patients receiving cisplatin due to the lack of evidence. The summary of evidence related to the effect of magnesium on CIN prevention is currently needed. Therefore, this systematic review and meta-analysis aimed to determine the clinical effect of magnesium supplementation on CIN prevention.

\section{MATERIALS AND METHODS}

This article was conducted according to the guidance of the Preferred Reporting Items for Systematic Reviews and Meta-analysis (PRISMA) statement. All meta-analyses were performed by using results from previously published studies, and thus no ethical approval and informed consent are required.

\subsection{Search strategy and selection criteria}

PubMed, Cochrane Library, Web of Science, Scopus, EMBASE and www.clinicaltrial.gov were searched for relevant studies up to February 2018. Strategic search terms were cisplatin, platinum*, and magnesium. The eligibility criteria were as follows: 1) studies conducted in adult patients diagnosed with solid tumor or hematologic malignancy who received cisplatin - based chemotherapy, 2) studies comparing the effect of magnesium supplementation with controls, and 3) studies reporting nephrotoxicity-related outcomes. No language restriction was applied. Titles and abstracts were screened according to the eligibility criteria. Full-text articles of potential studies were retrieved and were subsequently assessed independently by KD and PD. Any disagreements were settled by discussion and consensus.

\subsection{Data extraction and quality assessment}

Data extraction was undertaken by KD using a standard data extraction form and then verified by PD. The extracted data included study characteristics (first author, publication year, journal, study objective, study design, setting, country, diagnosis, and sample size), patients'characteristics, characteristics of intervention and comparator, and outcomes. The pre-specified primary outcome was severe nephrotoxicity, defined as grade 2 or more according to Common Terminology Criteria for Adverse Events, version 4.0 (CTCAE v.4.0.) ${ }^{28}$ Pre-specified secondary outcomes were the occurrence of any grades of nephrotoxicity and changes in $\mathrm{SCr}$ and $\mathrm{CrCl}$. Quality of included studies were assessed using the Revised Cochrane risk of bias tool for randomized trials (RoB 2.0) ${ }^{29}$ for randomized trials and Risk of Bias In Nonrandomized Studies of Interventions (ROBINSI) ${ }^{30}$ for non-randomized trial. The assessment was independently performed by KD and PD.

\subsection{Statistical analysis}

Meta-analyses were performed under the Der Simonian and Laird random-effects model ${ }^{31}$. The pooled relative risk with its corresponding $95 \%$ confidence interval $(95 \% \mathrm{CI})$ was presented for the occurrence of nephrotoxicity, while the pooled mean difference (MD) with its corresponding $95 \% \mathrm{CI}$ was presented for the changes in $\mathrm{SCr}$ and $\mathrm{CrCl}$. Heterogeneity was assessed by the $I^{2}$-statistic. Threshold of $I^{2}$ were interpreted in accordance with the magnitude and direction of effects and strength of evidence of heterogeneity. $P^{2}$-values greater than $50 \%$ indicated substantial heterogeneity ${ }^{32}$. Data from included studies were pooled using STATA version 15 (STATA Corp, College Station, TX, USA).

\section{RESULTS}

After identified through database searching and duplicate removed. We found a total 4,053 studies but only twelve studies ${ }^{8,17-27}$ were included in qualitative synthesis. Of those, ten studies provided sufficient data to perform 


\begin{tabular}{|c|c|c|c|c|c|c|c|c|}
\hline 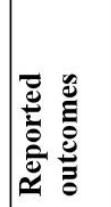 & 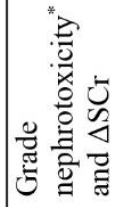 & 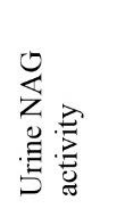 & 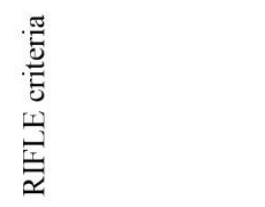 & 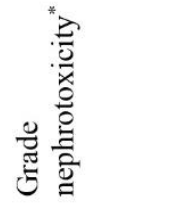 & 㺃 & 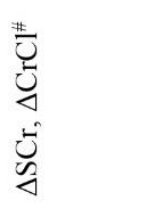 & 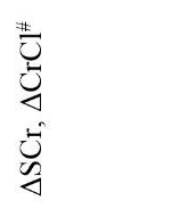 & 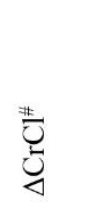 \\
\hline نَّ & 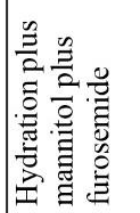 & 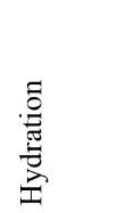 & 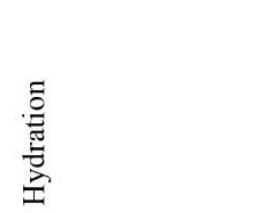 & 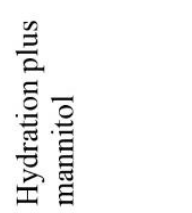 & 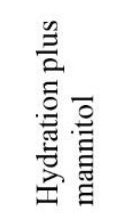 & 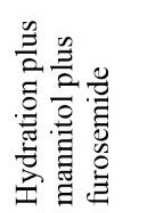 & 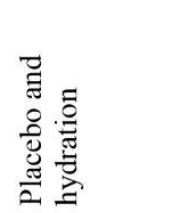 & 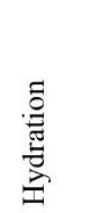 \\
\hline 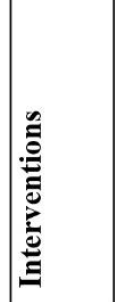 & 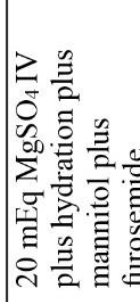 & 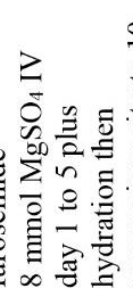 & 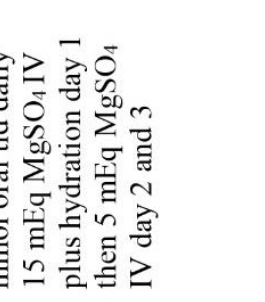 & 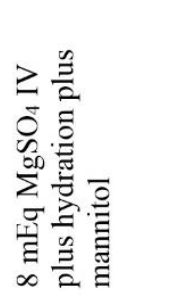 & 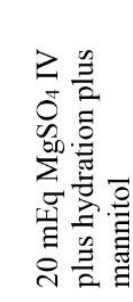 & 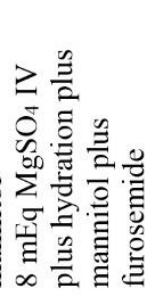 & 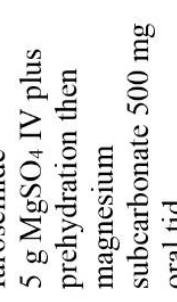 & 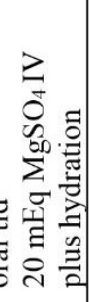 \\
\hline 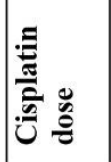 & 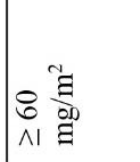 & 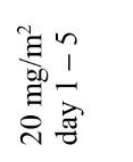 & 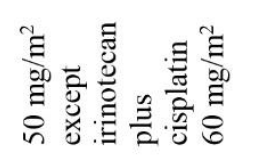 & 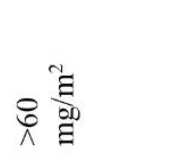 & $\begin{array}{l}\stackrel{\mathcal{Z}}{E} \\
\stackrel{\infty}{\Xi} \\
\stackrel{\infty}{0}\end{array}$ & 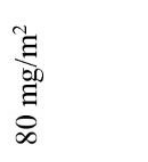 & 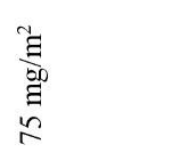 & 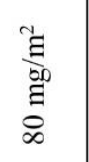 \\
\hline 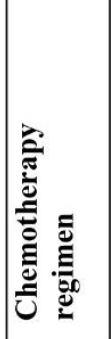 & 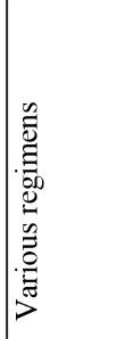 & 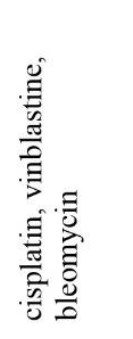 & 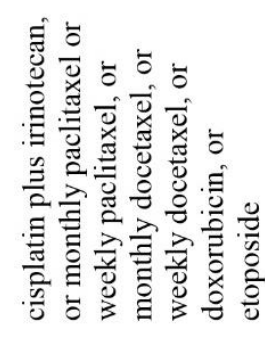 & 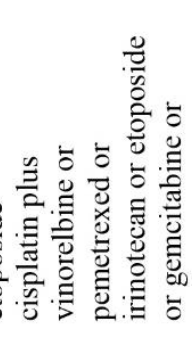 & 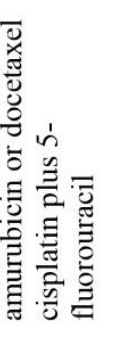 & 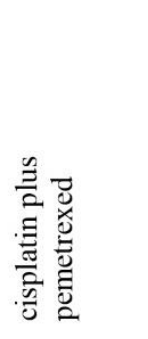 & 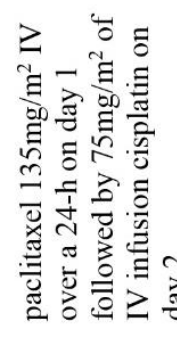 & 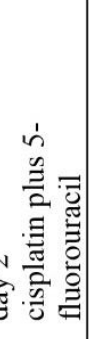 \\
\hline 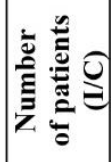 & $\frac{m}{\frac{m}{6}}$ & $\frac{\partial}{\infty}$ & $\frac{\hat{m}}{m}$ & $\stackrel{n}{m}$ & $\stackrel{m}{\Xi}$ & 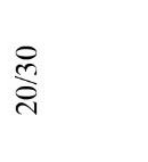 & 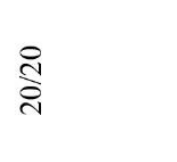 & $\begin{array}{l}n \\
\text { D. } \\
0\end{array}$ \\
\hline 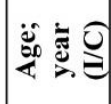 & 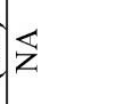 & $\stackrel{m}{\hat{N}}$ & 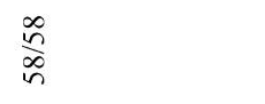 & $\begin{array}{l}\hat{0} \\
\text { fí }\end{array}$ & $\begin{array}{l}\text { : } \\
\text { ț }\end{array}$ & $\frac{8}{6}$ & $\underset{n}{m}$ & तु \\
\hline 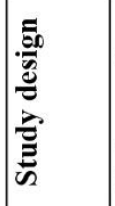 & 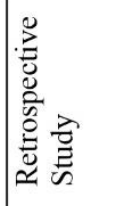 & 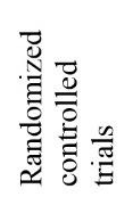 & 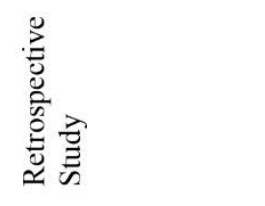 & 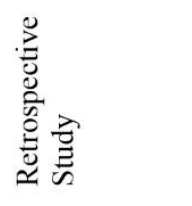 & 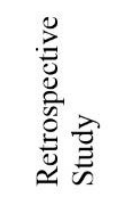 & 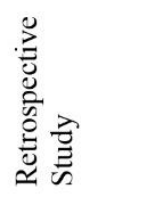 & 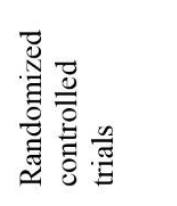 & 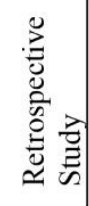 \\
\hline 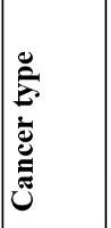 & 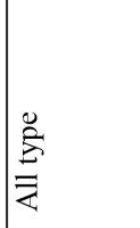 & 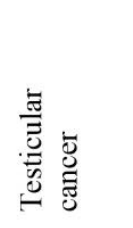 & 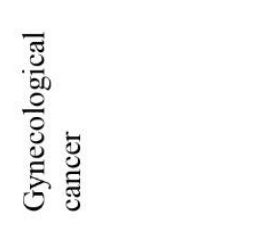 & 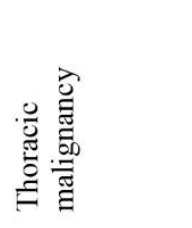 & 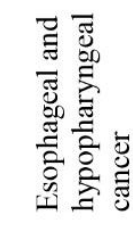 & 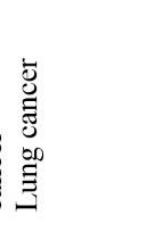 & 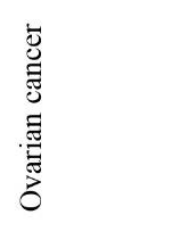 & 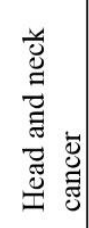 \\
\hline U⿺ & 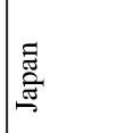 & $\breve{s}$ & 芯 & 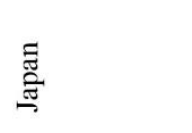 & 言 & 镸 & $\begin{array}{l}\overrightarrow{\tilde{J}} \\
\frac{\overrightarrow{5}}{0} \\
2\end{array}$ & 䓌 \\
\hline 会 & 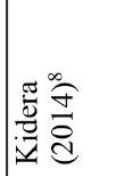 & 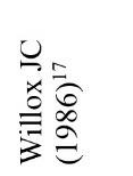 & 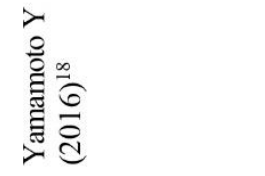 & 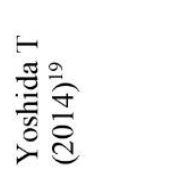 & 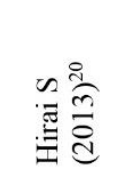 & 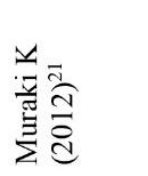 & 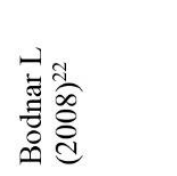 & 覓总 \\
\hline
\end{tabular}




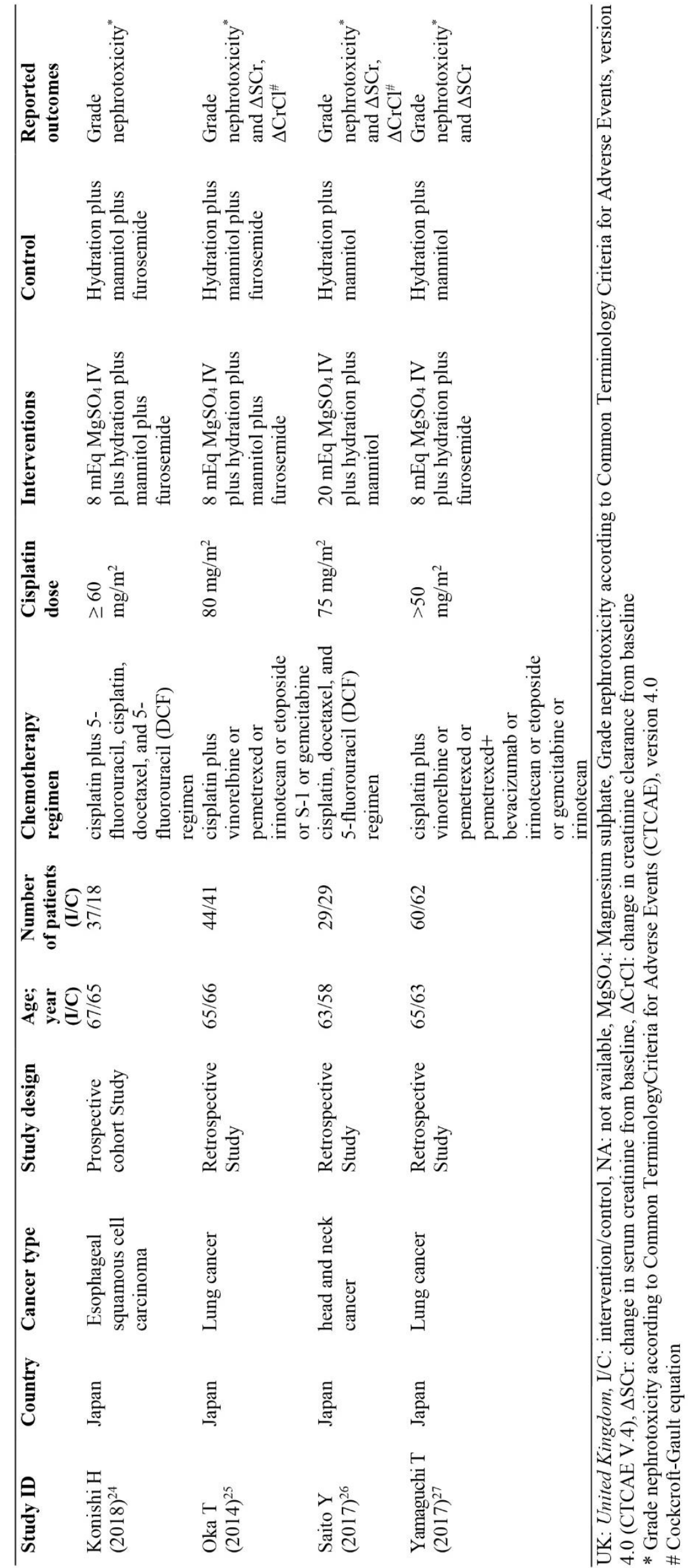


meta-analysis ${ }^{8,19-27}$ because 2 studies ${ }^{17-18}$ reported different nephrotoxic - related outcome from ten studies (Figure 1). Nine studies were retrospective observational studies ${ }^{8,18-21,23,25-27}$, whereas two studies were randomized controlled trials $(\mathrm{RCTs})^{17,22}$ and one study was prospective observational study ${ }^{24}$. All included studies were conducted in patients with solid tumors and receiving $\geq 50 \mathrm{mg} / \mathrm{m}^{2} /$ cycle of cisplatin-based chemotherapy. Intravenous magnesium sulfate $\left(\mathrm{MgSO}_{4}\right)$ administration (8-20 milliequivalence; $\mathrm{mEq}$ ) prior to chemotherapy initiation was used as intervention of interest for eleven included studies ${ }^{17-27}$. Only one study administered intravenous $\mathrm{MgSO}_{4}$ after chemotherapy ${ }^{8}$. Two studies also added oral magnesium supplementation afterwards ${ }^{17,22}$. Four studies reported both grade of nephrotoxicity and changes in $\mathrm{SCr}$ and/or $\mathrm{CrCl}^{8,25-27}$, while three studies reported only grade of nephrotoxicity ${ }^{19,20,24}$. Three studies reported only changes in $\mathrm{SCr}$ or/and $\mathrm{CrCl}^{21-23}$, and the other two studies reported other nephrotoxicity-related outcomes including urine N-acetyl- B-D-glucosaminidase (NAG) activity ${ }^{17}$ and Risk, Injury, Failure, Loss of kidney function and End-stage kidney disease (RIFLE) criteria ${ }^{18}$. The study characteristics of included studies were summarized in Table 1.
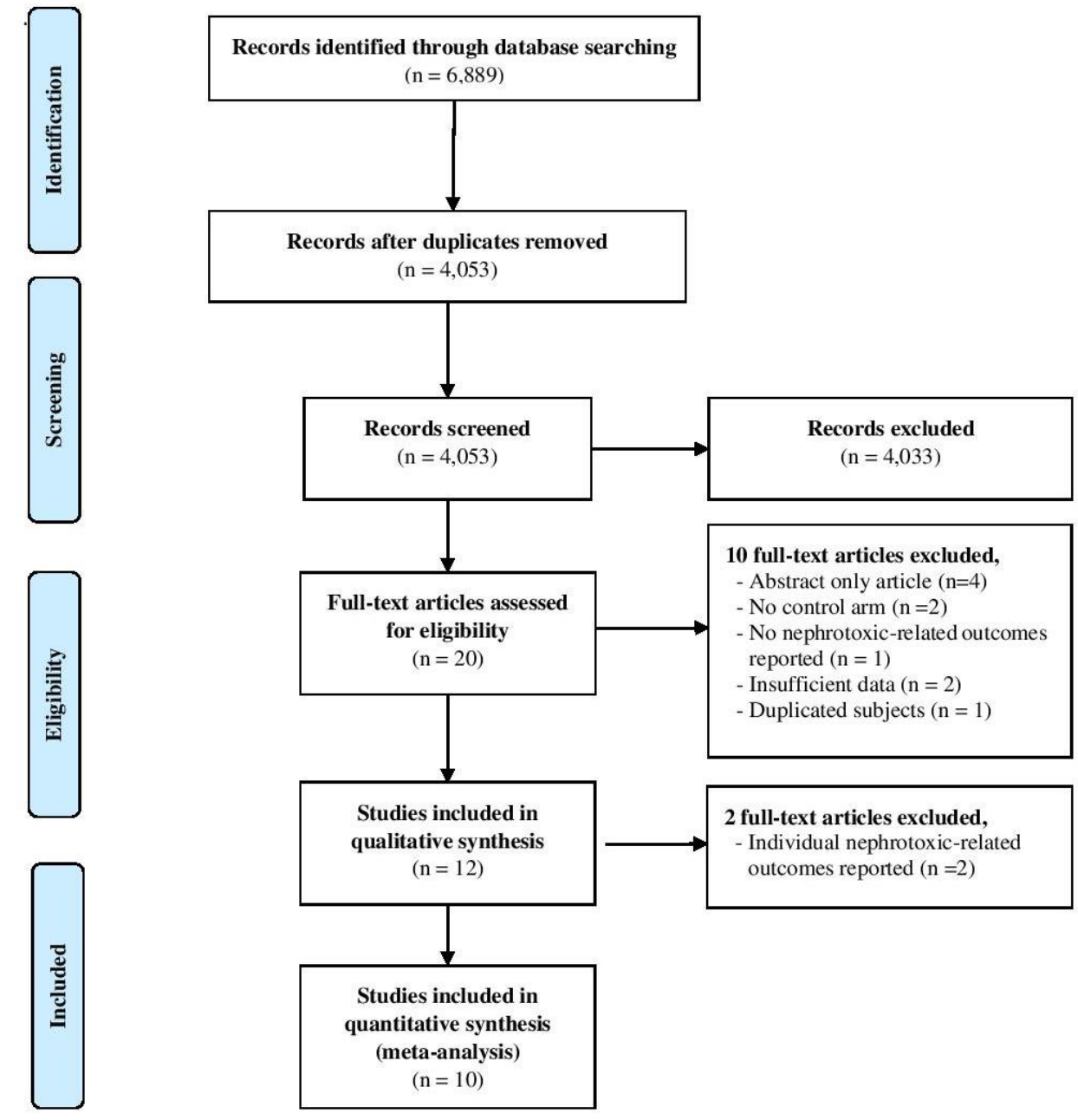

Figure 1. Flow diagram of literature retrieval and screening.

The quality of $\operatorname{RCTs}^{17,22}$ studies demonstrated some concerns risk of bias due to insufficient information regarding the randomization process, i.e., there was no mention of method of random sequence generation and allocation concealment in the studies. In addition, a study by
Willox JC et al did not report how the blinding process was performed ${ }^{17}$. The other ten observational studies ${ }^{8,18-21,23-27}$ had serious risk of bias because of the lack of appropriate confounding adjustment and outcome measurement. The detailed quality assessment scores were reported in Table 2 and 3. 
Table 2. Risk of bias assessment (Robin I).

\begin{tabular}{|c|c|c|c|c|c|c|c|c|}
\hline Study ID & $\begin{array}{l}\text { Bias due to } \\
\text { confounding }\end{array}$ & $\begin{array}{l}\text { Bias in } \\
\text { selection of } \\
\text { participants } \\
\text { into the study }\end{array}$ & $\begin{array}{l}\text { Bias in } \\
\text { classification of } \\
\text { interventions }\end{array}$ & $\begin{array}{l}\text { Bias due to } \\
\text { deviations } \\
\text { from intended } \\
\text { interventions }\end{array}$ & $\begin{array}{l}\text { Bias due to } \\
\text { missing } \\
\text { data }\end{array}$ & $\begin{array}{l}\text { Bias in } \\
\text { measurement } \\
\text { of outcomes }\end{array}$ & $\begin{array}{l}\text { Bias in } \\
\text { selection of } \\
\text { the reported } \\
\text { result }\end{array}$ & $\begin{array}{l}\text { Overall } \\
\text { bias }\end{array}$ \\
\hline Kidera & Serious & Low & Moderate & Low & Low & Serious & Moderate & Serious \\
\hline Yamamoto Y & Serious & Low & Moderate & Low & Low & Serious & Moderate & Serious \\
\hline Yoshida T & Serious & Low & Moderate & Low & Low & Serious & Moderate & Serious \\
\hline Hirai S & Serious & Low & Moderate & Low & Low & Serious & Moderate & Serious \\
\hline Muraki K & Serious & Low & Moderate & Low & Low & Serious & Moderate & Serious \\
\hline Kimura T & Serious & Low & Moderate & Low & Low & Serious & Moderate & Serious \\
\hline Konishi H & Serious & Low & Moderate & Low & Low & Serious & Moderate & Serious \\
\hline Oka T & Serious & Low & Moderate & Low & Low & Serious & Moderate & Serious \\
\hline Saito Y & Serious & Low & Moderate & Low & Low & Serious & Moderate & Serious \\
\hline Yamaguchi T & Serious & Low & Moderate & Low & Low & Serious & Moderate & Serious \\
\hline
\end{tabular}

Table 3. Risk of bias assessment (ROB II).

\begin{tabular}{|c|c|c|c|c|c|c|}
\hline Study ID & $\begin{array}{l}\text { Bias arising from the } \\
\text { randomization } \\
\text { process }\end{array}$ & $\begin{array}{l}\text { Bias due to } \\
\text { deviations } \\
\text { from intended } \\
\text { interventions }\end{array}$ & $\begin{array}{l}\text { Bias due to } \\
\text { missing } \\
\text { outcome data }\end{array}$ & $\begin{array}{l}\text { Bias in } \\
\text { measurement } \\
\text { of the outcome }\end{array}$ & $\begin{array}{l}\text { Bias in selection of } \\
\text { the reported result }\end{array}$ & Overall bias \\
\hline Bodnar L & Some concerns & Low & Low & Low & Low & Some concerns \\
\hline Willox JC & Some concerns & Some concerns & Low & Low & Low & Some concerns \\
\hline
\end{tabular}

Five studies ${ }^{19-20,24,26-27}$ reported severe nephrotoxicity for all cycle. The meta-analysis showed that the occurrence of severe nephrotoxicity for all chemotherapy cycles was significantly lower in magnesium-supplemented group compared to control group (RR 0.28,
$95 \% \mathrm{CI} ; 0.19$ to $\left.0.43 ; \mathrm{I}^{2}=0 \%\right)$. The effect was likely to be dose - dependent. The RRs of magnesium-supplemented groups receiving 20 and $8 \mathrm{mEq}$ of magnesium sulfate were 0.17 (95\% CI 0.02 to $\left.1.35 ; \mathrm{I}^{2}=0 \%\right)$ and $0.29(95 \% \mathrm{CI} 0.19$ to $0.45 ; \mathrm{I}^{2}=0 \%$ ), respectively (Figure 2 ).

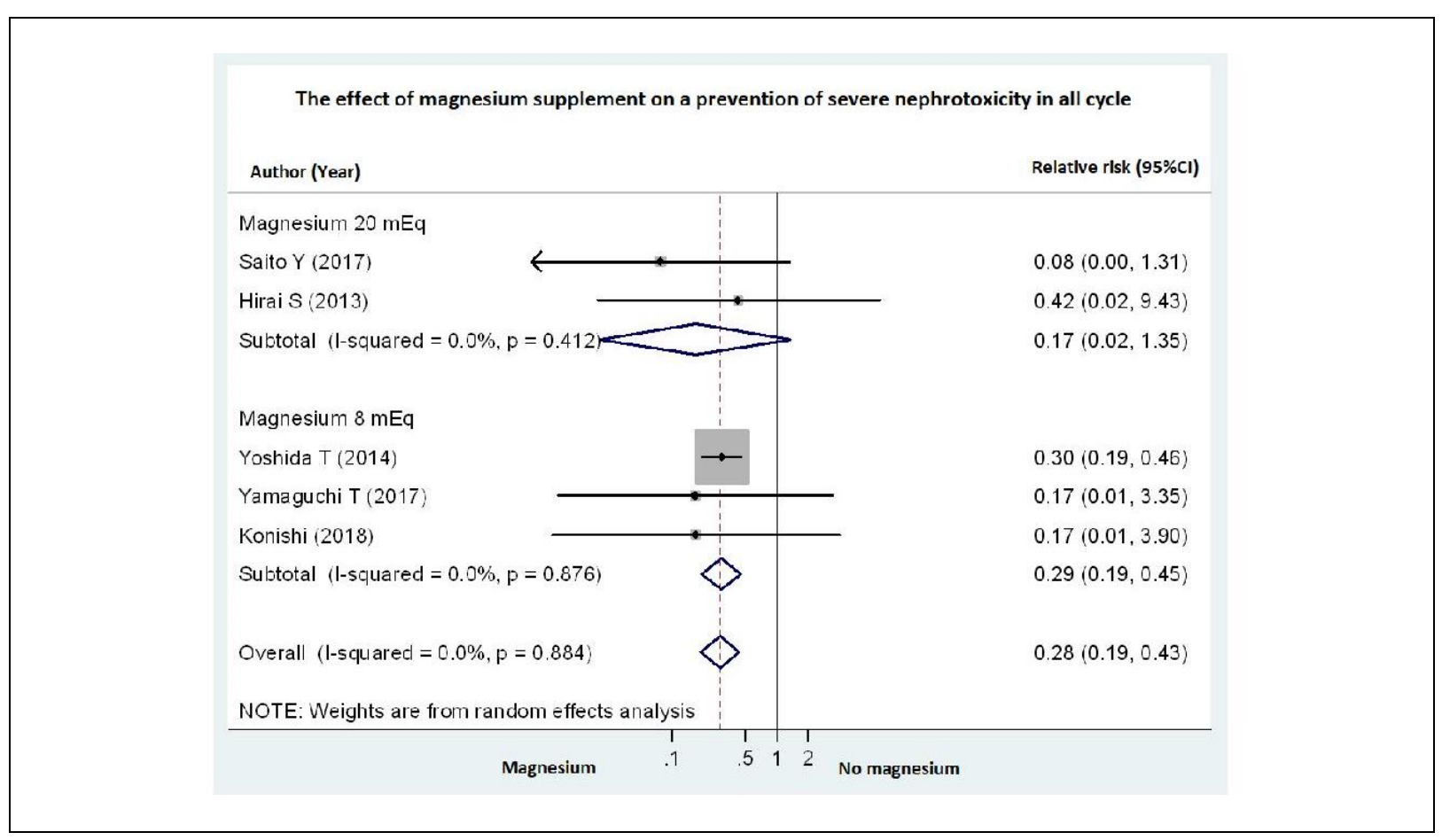

Figure 2. The effect of magnesium supplement on a prevention of severe nephrotoxicity* in all cycle.

Note: Severe nephrotoxicity was defined grade 2 or more of Common Terminology Criteria for Adverse Events (CTCAE) version 4.0. 


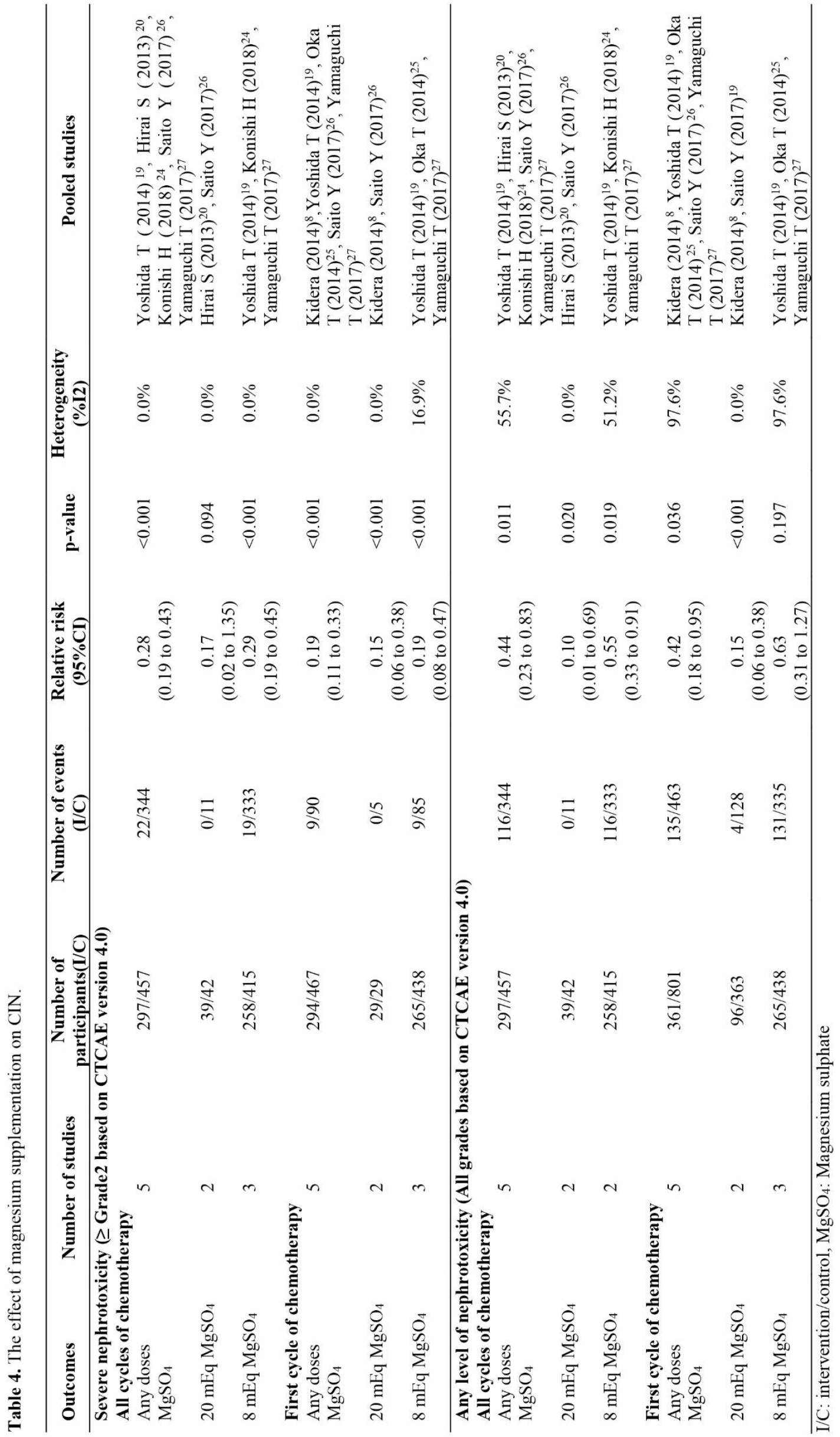


The occurrence of severe nephrotoxicity for the first chemotherapy cycle of patients was also significantly lower in magnesium supplement group (RR $0.19,95 \% \mathrm{CI} 0.11$ to $0.33 ; \mathrm{I}^{2}=0 \%$ ) and the nephroprotective effect was likely to be dose - dependent ${ }^{8,19,25-27}$ (Figure 3). Similar to severe nephrotoxicity, the occurrence of all levels of nephrotoxicity was lower in magnesium-supplemented group. The RR of all levels of nephrotoxicity for all cycles was $0.44(95 \% \mathrm{CI} 0.23$ to 0.83 ; $\mathrm{I}^{2}=55.7 \%$ ), while that for the first cycle was $0.42\left(95 \%\right.$ CI 0.18 to $\left.0.95 ; \mathrm{I}^{2}=97.6 \%\right)$. The effect of magnesium supplement on a prevention of CIN both all cycle and the first cycle were presented in Table 4.

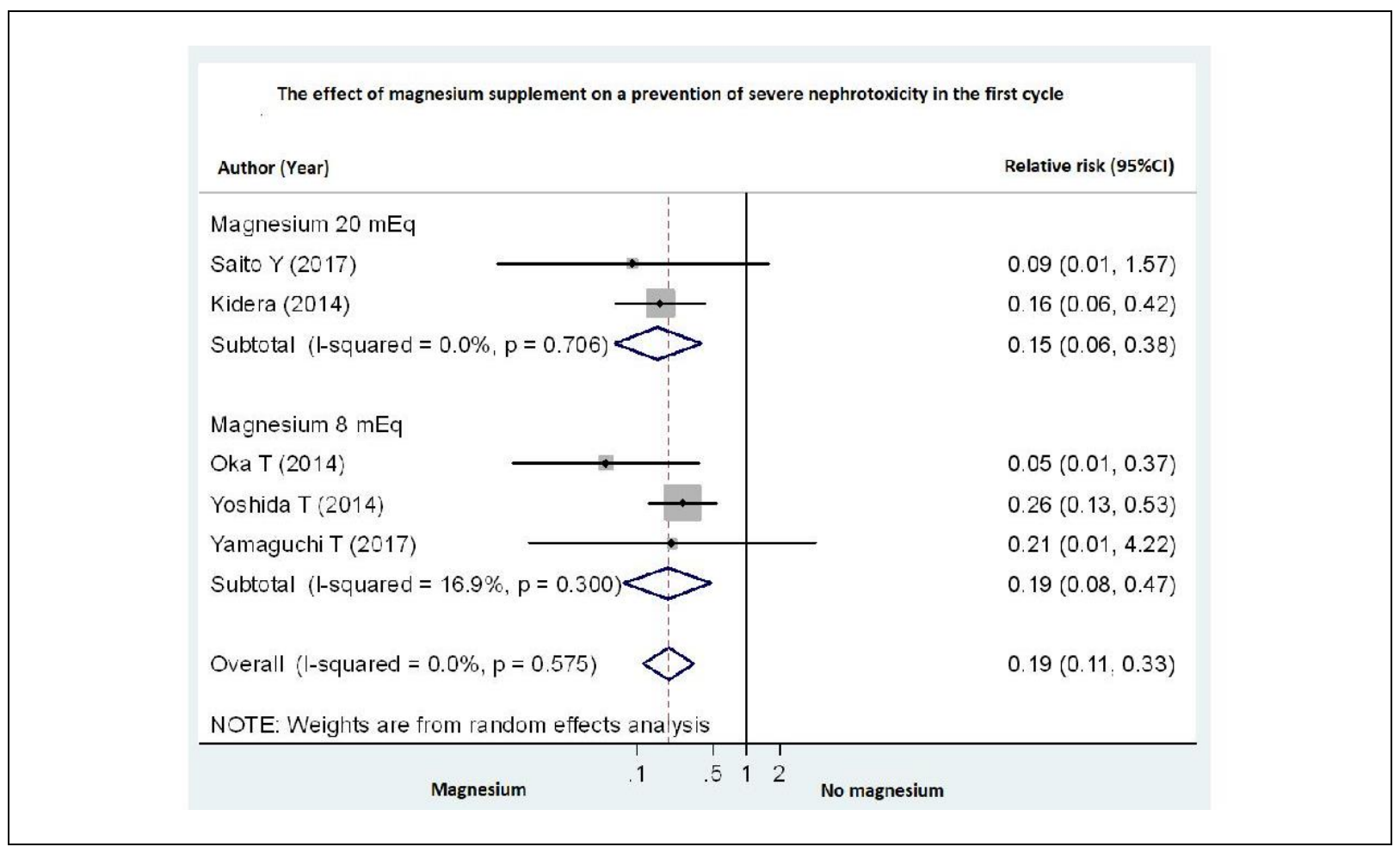

Figure 3. The effect of magnesium supplement on a prevention of severe nephrotoxicity* in first cycle.

Note: Severe nephrotoxicity was defined grade 2 or more of Common Terminology Criteria for Adverse Events (CTCAE) version 4.0.

Seven studies provided data on changes in $\mathrm{SCr}$ and/or $\mathrm{CrCl}^{8,21-23,25-27}$. Our meta-analysis indicated that the increase in $\mathrm{SCr}$ in patients with magnesium supplementation was significantly lower than that in patients with control $(\mathrm{MD}=$ $0.2,95 \% \mathrm{CI}-0.27$ to $-0.13 ; \mathrm{I}^{2}=60.1 \%$ ) for all chemotherapy cycles. This result was in line with its protective effect on CIN. Similar to the analysis of all chemotherapy first cycles, the increase in $\mathrm{SCr}$ in patients with magnesium supplementation was also significantly lower than that in patients with control ( $\mathrm{MD}=-0.19,95 \% \mathrm{CI}-0.25$ to -0.12 ; $\mathrm{I}^{2}=88.6 \%$. Magnesium supplementation also significantly prevented the decrease in $\mathrm{CrCl}$ for all chemotherapy cycles and the first cycles. Mean differences of the decrease in $\mathrm{CrCl}$ for all cycles and for the first cycle were -11.33 (95\% CI - 14.15 to $\left.-8.51 ; \mathrm{I}^{2}=0.0 \%\right)$ and $-12.02(95 \% \mathrm{CI}-14.83$ to $9.22 ; \mathrm{I}^{2}=0.0 \%$ ), respectively. The mean differences of both all cycle and the first cycle were presented in Table 5.
A study by Willox $\mathrm{JC}$ et $\mathrm{al}^{17}$ reported the effect of magnesium supplementation on CIN by measuring urine NAG activity. Higher urine NAG activity indicated higher nephrotoxicity. The study reported that magnesium supplementation significantly reduced the urine NAG activity compared to control by the third cycle of chemotherapy $(\mathrm{P}<0.01)$. Another study by Yamamoto $\mathrm{Y}$ et al ${ }^{18}$ reported the nephroprotective effect of $15 \mathrm{mEq}$ magnesium supplementation on CIN using the RIFLE criteria. The study showed that the number of patients with moderate renal dysfunction, which was defined as an increase in SCr of $\geq 50 \%$ or a decrease in $\mathrm{CrCl}$ of $\leq 25 \%$ was significantly lower in patients with magnesium supplementation compared to controls $(21.6 \% \mathrm{vs}$. $51.4 \%$; $\mathrm{P}<0.01)$. However, the number of patients with severe renal dysfunction, which was defined as increase in $\mathrm{SCr}$ of $\geq 100 \%$ or a decrease in $\mathrm{CrCl}$ of $\leq 50 \%$, was not statistically different $(8.1 \%$ vs. $16.2 \% ; \mathrm{P}=0.29)$. 
Pharmaceutical Sciences Asia

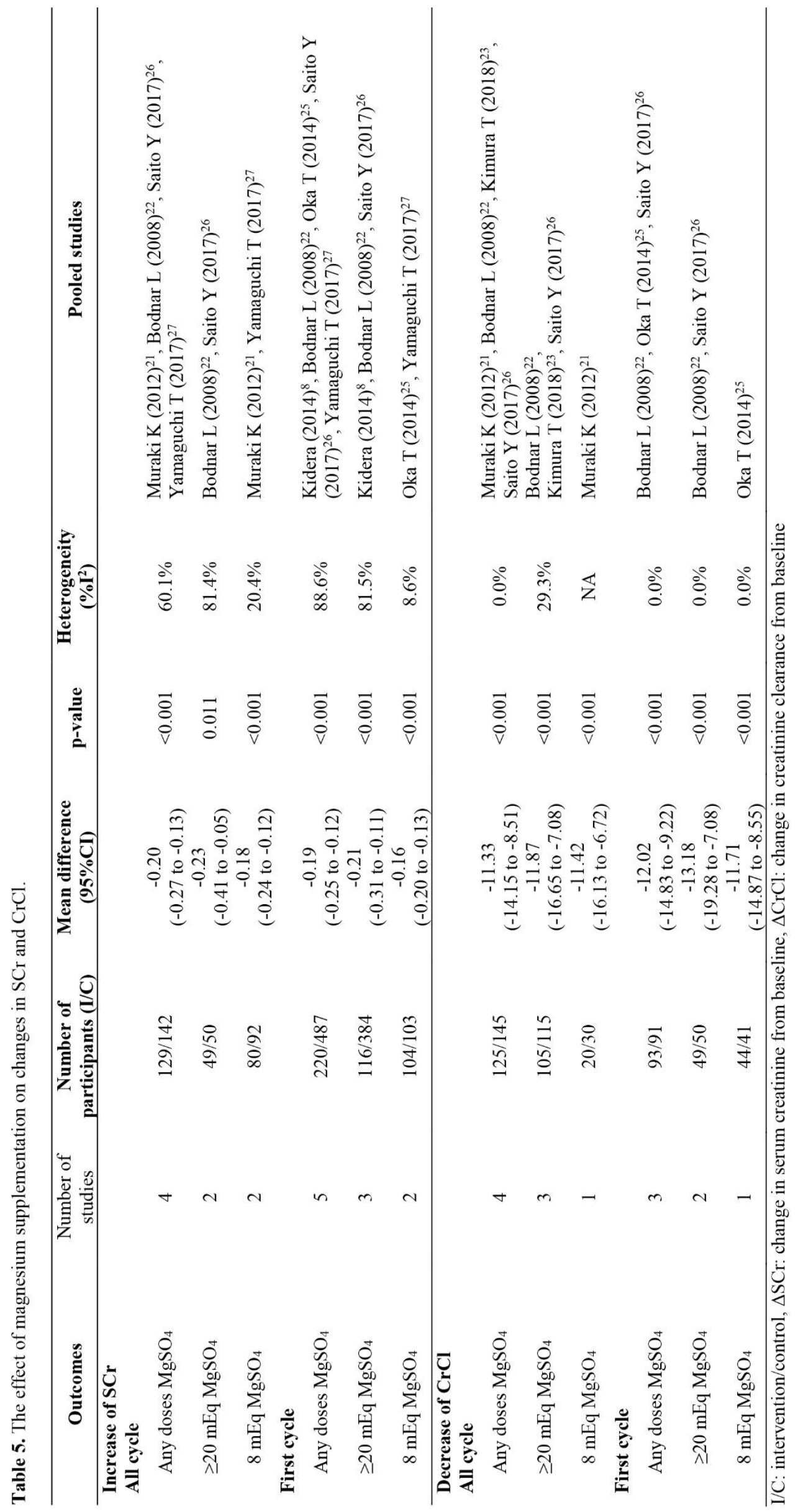




\section{DISCUSSION}

Our systematic review and meta-analysis provided a most updated and comprehensive evidence of magnesium supplementation on prevention of CIN. We observed that a supplementation of $8-20 \mathrm{mEq}$ magnesium of any cycle of cisplatin-based chemotherapy could reduce the risk of nephrotoxicity induced by cisplatin, especially for severe nephrotoxicity.

Cisplatin has been widely used for treatment of several types of solid tumors. However, nephrotoxicity is one of the major dose-limiting adverse effects. Cisplatin is excreted in the urine via glomerular filtration and tubular secretion. The secretion of cisplatin in the proximal tubules is mediated by various transporters. In humans, cisplatin enters the tubular cells from basolateral side via organic cation transporters 2 (OCT2), accumulates in these cells, and then transports into the urine at the apical side via multidrug and toxin extrusion (MATE) transporters. Some OCT2 inhibitors such as cimetidine and corticosterone have been demonstrated to decrease the cytotoxicity and renal toxicity induced by cisplatin ${ }^{33}$. Direct damage to renal tubules by cisplatin often causes acute kidney injury (20-30\%) and affects renal reabsorptive capacity including magnesium reabsorption, resulting in renal magnesium wasting and hypomagnesemia (40-100\%) ${ }^{4}$. Furthermore, hypomagnesemia can worsen the nephrotoxicity by enhancing the renal accumulation of cisplatin via upregulation of OCT2 ${ }^{34}$. Therefore magnesium supplementation for prevention of hypomagnesemia might be beneficial in cisplatin treatment.

Most of the included studies were conducted in patients receiving high - dose cisplatin $\left(>50 \mathrm{mg} / \mathrm{m}^{2}\right)$. Therefore, magnesium supplementation might be benefit in these patients, probably due to the significant decreases in glomerular filtration rate (GFR) and magnesium levels ${ }^{35}$. The administration of magnesium supplementation for prevention of CIN should be considered. Intravenous administration is preferred. A previous study showed that intravenous and oral administration were equivalent in terms of increasing in serum magnesium level but oral administration increased risk of gastrointestinal tract adverse effects ${ }^{36}$.

The administration of intravenous magnesium supplementation before cisplatinbased chemotherapy showed the benefits in almost studies. One of the possible reasons is that cisplatin affects the kidney within 6 hours after cisplatin - based chemotherapy initiation. Urinary markers of proximal tubulotoxicity increased within 3 - 6 hours after the chemotherapy ${ }^{37}$. Some studies added oral magnesium after the first intravenous dose. However, there is no evidence directly compared the effect of intravenous magnesium alone to that of the addition of oral magnesium on CIN prevention.

The European Society of Clinical Pharmacy Special Interest Group on Cancer Care guideline suggested magnesium supplementation based on limited evidencev ${ }^{38}$. Our findings supported the suggestion abovementioned. In addition, we found that 8 to $20 \mathrm{mEq}$ of intravenous magnesium should be supplemented without the increased risk of hypermagnesemia ${ }^{17,22}$.

Some limitations of this study should be addressed. First, most included studies were observational studies which had high risk of bias. It may affect the credibility of our findings. Second, we included only 10 studies for metaanalysis. Therefore, statistical publication bias assessment could not be performed. However, based on our searches which included most of major databases including PubMed, Cochrane Library, Web of Science, Scopus, and EMBASE. In addition, we searched for grey literature in clinicaltrial.gov. Thus, we believe that our search was comprehensive to minimize publication bias. Third, included studies had different regimen for hydration to prevent nephrotoxicity which might affect our findings. Forth, most included studies did not provide the information regarding any comedications affecting nephrotoxic effect including nonselective nonsteroidal antiinflammatory drugs as well as other risk factors for nephrotoxicity. Last, most included studies did not report magnesium level data before and after treatment. Therefore, the magnesium level could not be used as a factor for subgroup analysis. Applying our findings should be done with cautions.

\section{CONCLUSIONS}

Our most updated findings support the use of magnesium supplementation as a pre hydration to prevent CIN, especially for severe nephrotoxicity. Oncologists might consider adding $8-20 \mathrm{mEq}$ magnesium in patients receiving a cumulative dose of $\geq 50 \mathrm{mg} / \mathrm{m}^{2}$ of cisplatin. However, because of limited number of studies and their qualities. Further highquality randomized controlled studies should be 
conducted to confirm such effects.

\section{ACKNOWLEDGEMENTS}

The authors would like to acknowledge of Mr. Perter Barton, Division of international Affairs and Language Development (DIALD), Naresuan University, Thailand, for their useful suggestions to the language and structure of the manuscripts.

\section{CONFLICT OF INTEREST}

The authors declared no potential conflicts of interest with respect to the research, authorship, and/or publication of this article.

\section{Funding}

This research received no specific grant from any funding agency in the public, commercial, or notfor-profit sectors.

\section{Ethical approval}

None to declare.

\section{Article info:}

Received June 24, 2019

Received in revised form November 29,2019

Accepted March 30, 2020

\section{REFERENCES}

1. Pabla N, Dong Z. Cisplatin nephrotoxicity: Mechanisms and renoprotective strategies. Kidney Int. 2008;73:994-1007.

2. Prasaja $Y$, Sutandyo N, Andrajati R. Incidence of cisplatin-induced nephrotoxicity and associated factors among cancer patients in indonesia. Asian Pac J Cancer Prev. 2015;16:1117-22.

3. Yao X, Panichpisal K, Kurtzman N, Nugent K. Cisplatin nephrotoxicity: A review. Am J Med Sci. 2007;334:115-24.

4. Miller RP, Tadagavadi RK, Ramesh G, Reeves WB. Mechanisms of cisplatin nephrotoxicity. Toxins (Basel). 2010;2:2490-518.

5. Yamamoto Y, Watanabe K, Matsushita H, Tsukiyama I, Matsuura K, Wakatsuki A. Multivariate analysis of risk factors for cisplatin-induced nephrotoxicity in gynecological cancer. J Obstet Gynaecol Res. 2017;43:1880-6.

6. Hayati F, Hossainzadeh M, Shayanpour S, AbediGheshlaghi Z, Beladi Mousavi SS. Prevention of cisplatin nephrotoxicity. J Nephropharmacol. 2016;5:57-60.

7. Kobayashi R, Suzuki A, Matsuura K, Yamada N, Nakano M, Deguchi T, et al. Risk analysis for cisplatininduced nephrotoxicity during first cycle of chemotherapy. Int J Clin Exp Med. 2016;9:3635-41.

8. Kidera Y, Kawakami H, Sakiyama T, Okamoto K, Tanaka K, Takeda M, et al. Risk factors for cisplatin-induced nephrotoxicity and potential of magnesium supplementation for renal protection. PLoS One. 2014;9(7):e101902.

9. Crona DJ, Faso A, Nishijima TF, McGraw KA, Galsky MD, Milowsky MI. A systematic review of strategies to prevent cisplatin-induced nephrotoxicity. Oncologist. 2017;22:609-19.

10. Hodgkinson E, Neville-Webbe HL, Coleman RE. Magnesium depletion in patients receiving cisplatin-based chemotherapy. Clin Oncol (R Coll Radiol). 2006;18:710-18.
11. Yamamoto Y, Watanabe K, Matsushita H, Tsukiyama I, Matsuura K, Wakatsuki A. The incidence of cisplatininduced hypomagnesemia in cervical cancer patients receiving cisplatin alone. Yakugaku Zasshi. 2017;137:79-82.

12. Bell DR, Woods RL, Levi JA. cis-Diamminedichloroplatinuminduced hypomagnesemia and renal magnesium wasting. Eur J Cancer Clin Oncol. 1985;21:287-90.

13. Ashraf M, Scotchel PL, Krall JM, Flink EB. cisPlatinum-induced hypomagnesemia and peripheral neuropathy. Gynecol Oncol. 1983;16:309-18.

14. Saito Y, Okamoto K, Kobayashi M, Narumi K, Furugen A, Yamada T et al. Magnesium co-administration decreases cisplatin-induced nephrotoxicity in the multiple cisplatin administration. Life Sci. 2017;189:18-22.

15. Ashrafi F, Haghshenas S, Nematbakhsh M, Nasri H, Talebi A, Eshraghi-Jazi $\mathrm{F}$, et al. The role of magnesium supplementation in cisplatin-induced nephrotoxicity in a rat model:no nephroprotectant effect. Int J Prev Med. 2012;3:637-43.

16. Solanki MH, Chatterjee PK, Xue X, Gupta M, Rosales I, Yeboah MM, et al. Magnesium protects against cisplatininduced acute kidney injury without compromising cisplatin-mediated killing of an ovarian tumor xenograft in mice. Am J Physiol Renal Physiol. 2015;309:F35-47.

17. Willox JC, McAllister EJ, Sangster G, Kaye SB. Effects of magnesium supplementation in testicular cancer patients receiving cis-platin: a randomised trial. $\mathrm{Br} \mathbf{~}$ Cancer. 1986;54:19-23.

18. Yamamoto Y, Watanabe K, Tsukiyama I, Yabushita H, Matsuura K, Wakatsuki A. Hydration with $15 \mathrm{mEq}$ magnesium is effective at reducingthe risk for cisplatininduced nephrotoxicity in patients receiving cisplatin $(\geq 50 \mathrm{mg} / \mathrm{m} 2)$ combination chemotherapy. Anticancer Res. 2016;36:1873-77.

19. Yoshida T, Niho S, Toda M, Goto K, Yoh K, Umemura $\mathrm{S}$, et al. Protective effect of magnesium preloading on cisplatin-induced nephrotoxicity: a retrospective study. Jpn J Clin Oncol. 2014;44:346-54.

20. Hirai S, Kaida S, Ito T, Hasebe S, Ueno M, Udagawa H, et al. Magnesium premedication prevents cisplatininduced nephrotoxicity in patients with esophageal and hypopharyngeal cancer. Gan To Kagaku Ryoho. 2013;40:743-7.

21. Muraki K, Koyama R, Honma Y, Yagishita S, Shukuya $\mathrm{T}$, Ohashi R, et al. Hydration with magnesium and mannitol without furosemide prevents the nephrotoxicity induced by cisplatin and pemetrexed in patients with advanced non-small cell lung cancer. J Thorac Dis. 2012;4:562-8.

22. Bodnar L, Wcislo G, Gasowska-Bodnar A, Synowiec A, Szarlej-Wcisło K, Szczylik C. Renal protection with magnesium subcarbonate and magnesium sulphate in patients with epithelial ovarian cancer after cisplatin and paclitaxel chemotherapy: A randomised phase II study. Eur J Cancer. 2008;44:2608-14.

23. Kimura T, Ozawa T, Hanai N, Hirakawa H, Suzuki H, Hosoi $\mathrm{H}$, et al. Renal protective effect of a hydration supplemented with magnesium in patients receiving cisplatin for head and neck cancer. J Otolaryngol Head Neck Surg. 2018;47(1):10.

24. Konishi H, Fujiwara H, Itoh H, Shiozaki A, Arita T, Kosuga $\mathrm{T}$, et al. Influence of magnesium and parathyroid hormoneon cisplatin induced nephrotoxicity in esophageal squamous cell carcinoma. Oncol Lett. 2018;15:658-64.

25. Oka T, Kimura T, Suzumura T, Yoshimoto N, Nakai T, Yamamoto N, et al. Magnesium supplementation and high volume hydration reduce the renal toxicity caused by 
cisplatin-based chemotherapy in patients with lung cancer: a toxicity study. BMC Pharmacol Toxico. 2014;15:70.

26. Saito Y, Kobayashi M, Yamada T, Kasashi K, Honma R, Takeuchi S, et al. Premedication with intravenous magnesium has a protective effect against cisplatin-induced nephrotoxicity. Support Care Cancer. 2017;25:481-7.

27. Yamaguchi T, Uozu S, Isogai S, Hayashi M, Goto Y, Nakanishi $\mathrm{T}$, et al. Short hydration regimen with magnesium supplementation prevents cisplatin-induced nephrotoxicity in lung cancer: a retrospective analysis. Support Care Cancer. 2017;25:1215-20.

28. The National Cancer Institute (NCI) of the National Institutes of Health (NIH). Common Terminology Criteria for Adverse Events (CTCAE) Version 4.0.2010 [cited 2019 April 30], Available from: http://www. hrc.govt.nz/sites/default/files/CTCAE\%20manual\%20$\% 20$ DMCC.pdf.

29. Higgins JPT, Savović J, Page MJ, Sterne JAC and the development group for RoB 2.0. Revised Cochrane risk of bias tool for randomized trials (RoB 2.0). 2019 [cited 2019 April 30]. Available from: https://www.riskofbias.info/welcome/ rob-2-0-tool/current-version-of-rob-2.

30. Sterne JAC, Higgins JPT, Elbers RG, BC R and the development group for ROBINS-I. Risk Of Bias In Nonrandomized Studies of Interventions (ROBINS-I): detailed guidance. 2016 [cited 2019 April 30]. Available from: http://www.riskofbias.info.

31. DerSimonian R, Laird N. Meta-analysis in clinical trials. Control Clin Trials. 1986;7:177-88.
32. Higgins JP, Thompson SG, Deeks JJ, Altman DG. Measuring inconsistency in meta-analyses. BMJ. 2003;327:557-60.

33. Harrach S, Ciarimboli G. Role of transporters in the distribution of platinum-based drugs. Front Pharmacol. 2015;6:85

34. Yokoo K, Murakami R, Matsuzaki T, Yoshitome K, Hamada A, Saito H. Enhanced renal accumulation of cisplatin via renal organic cation transporter deteriorates acute kidney injury in hypomagnesemic rats. Clin Exp Nephrol. 2009;13:578-84.

35. Hartmann JT, Kollmannsberger C, Kanz L, Bokemeyer C. Platinum organ toxicity and possible prevention in patients with testicular cancer. Int $\mathbf{J}$ Cancer. 1999;83:866-9.

36. Martin M, Diaz-Rubio E, Casado A, López Vega JM, Sastre J, Almenarez J. Intravenous and oral magnesium supplementations in the prophylaxis of cisplatininduced hypomagnesemia. Results of a controlled trial. Am J Clin Oncol. 1992;15:348-51.

37. Bunel V, Tournay Y, Baudoux T, De Prez E, Marchand M, Mekinda Z, et al. Early detection of acute cisplatin nephrotoxicity: interest of urinary monitoring of proximal tubular biomarkers. Clin Kidney J. 2017;10:639-47.

38. Launay-Vacher V, Rey JB, Isnard-Bagnis C, Deray G, Daouphars M, European Society of the art and recommendations from the European Society of Clinical Pharmacy Special Interest Group on Cancer Care. Cancer Chemother Pharmacol. 2008;61:903-9. 